\title{
Quality of life analysis after Whipple procedure. Retrospective cohort study
}

\author{
Análisis de calidad de vida en cirugía Whipple. Estudio de cohorte retrospectiva \\ Juan Pablo Aristizábal-Linares ${ }^{\mathrm{a}}$ (D) , Cristina Quevedo-Vélez ${ }^{\mathrm{a}}$, Paola Sánchez-Zapatab ${ }^{\mathrm{B}}$ \\ a Clínica CES. Medellín, Colombia \\ b Universidad CES, Medellín, Colombia
}

Correspondence: Calle 58 \# 50C-2, Prado Centro. Medellín, Colombia. E-mail: Juanpablo.aristizabal@gmail.com

\section{What do we know about this problem?}

Patient reported outcomes (PRO) are effectively measured using questionnaires, apps or over the phone interviews, and measure the quality of life and the overall perception about the health status.

Multiple trials have shown the adoption of PRO following cephalic duodenopancreatectomy (DPC), with controversial reports in terms of quality of life and going back to normal everyday life activities.

\section{What does this new trial contribute?}

- Study in Latin population adopting PRO following DPC, using the EQ-5D-5L questionnaire, compared against a control group.

- The overall health perception following DPC is slightly lower than in patients undergoing laparoscopic cholecystectomy.

- The differences in quality of life perception are based on: increased pain, presence of anxiety/depressionand disruption of activities of daily life.

How to cite this article:

Aristizábal-Linares JP, Quevedo-Vélez C, Sánchez-Zapata P. Quality of life analysis after Whipple procedure. Retrospective cohort study. Colombian Journal of Anesthesiology. 2021;49:e946.

\section{Abstract}

\section{Introduction}

Patient reported outcomes establish the patient's own perception about his/her health and enable the development of policies designed to improve health/disease processes. These are particularly helpful in the case of diseases with a significant impact on the patient's quality of life.

\section{Objective}

To compare the quality of life scores assessed using the EQ-5D-5L questionnaire in patients undergoing cephalic duodenopancreatectomy (Whipple procedure) and laparoscopic cholecystectomies in the same hospital.

\section{Methodology}

Retrospective cohort trial between July 2018 and February 2020. Patients programmed for cephalic duodenopancreatectomy were included, regardless of the type of pathology, and over 18 years old. Patients with carcinomatosis or vascular infiltration were excluded. The EQ-5D-5L was administered following Whipple surgery and compared against a control group (laparoscopic cholecystectomy). The demographic characteristics, the diagnosis, hospital stay and 60-day mortality were assessed.

\section{Results}

A total of 68 patients were included. The most frequent diagnosis was pancreatic cancer (30\%) in the Whipple group and lithiasis (100\%) in the control group. In the five dimensions assessed, there were no differences in terms of mobility (OR: 0.41, 95 $\% \mathrm{Cl}$ [0.30-0.57], $\mathrm{p}=0.103$ ) and in terms of personal care (OR: $0.42,95 \% \mathrm{Cl}$ [0.32-0.58], $\mathrm{p}=0.254$ ). There was a difference in daily life activities (OR: $0.38,95 \% \mathrm{Cl}[0.27-0.54], \mathrm{p}$ $=0.017)$, pain/malaise (OR: $2.33,95 \% \mathrm{Cl}[0.99-5.48]), p=0.013$ and anxiety/depression (OR: $0.39,95 \% \mathrm{Cl}[0.28-0.55], \mathrm{p}=0.019$ ). The overall health perception was 80 points for Whipple (IQR 60-90) vs. 100 points for the control group (IQR 90-100).

\section{Conclusions}

Patients undergoing a Whipple procedure experience a health perception slightly lower than patients undergoing laparoscopic cholecystectomy. This difference may be associated with increased pain, anxiety/depression and a reduction in their activities of daily life. The administration of the EQ-5D-5L questionnaire to measure quality of life is a friendly tool that used be used routinely to plan activities aimed at improving medical care.

\section{Keywords}

Pancreaticoduodenectomy; quality of life; morbidity; patient reported outcome measures; neoplasm. 


\section{Resumen}

Introducción

Los desenlaces informados por el paciente permiten establecer cuál es la percepción que tiene de su salud y crear políticas que mejoren procesos en salud/enfermedad. Son particularmente útiles en enfermedad que afectan la calidad de vida de forma importante.

\section{Objetivo}

Comparar las puntuaciones de calidad de vida evaluadas mediante el cuestionario EQ-5D-5L en pacientes sometidos a duodenopancreatectomía cefálica (procedimiento de Whipple) y colecistectomías laparoscópicas en el mismo centro hospitalario.

\section{Metodología}

Estudio de cohorte retrospectivo entre julio de 2018 y febrero de 2020. Se incluyeron pacientes programados para duodenopancreatectomía cefálica independientemente del tipo de patología y mayor de 18 años de edad; se excluyeron pacientes con carcinomatosis o infiltración vascular. Se aplicó el cuestionario EQ-5D-5L después de cirugía Whipple y se comparó con un grupo control (colecistectomía laparoscópica). Se evaluaron características demográficas, diagnóstico, estancia hospitalaria y mortalidad a 60 días.

\section{Resultados}

Se incluyeron 68 pacientes. El diagnóstico más frecuente fue cáncer de páncreas (30 \%) en el grupo Whipple y litiasis (100 \%) en el grupo control. En las 5 dimensiones evaluadas no hubo diferencias en movilidad (OR: 0,41, IC $95 \%$ [0,30-0,57], $p=0,103$ ) y en cuidado personal (OR: 0,42 , IC $95 \%$ [0,32-0,58], p = 0,254). Se encontró diferencia en actividades cotidianas (OR: 0,38, IC $95 \%$ [0,27-0,54], p= 0,017), dolor/malestar (OR: 2,33, IC $95 \%$ [0,99-5,48]), $p=0,013$ y angustia/depresión (OR: 0,39, IC $95 \%$ [0,28-0,55], $p=0,019$ ). La percepción general de salud fue 80 puntos para Whipple (RIQ60-90) vs. 100 puntos para el grupo control (RIC 90-100).

\section{Conclusiones}

Los pacientes sometidos a Whipple presentan una percepción de salud ligeramente menor que los pacientes de colecistectomía laparoscópica. Esta diferencia puede estar relacionada con el aumento en dolor, angustia/depresión y disminución en actividades cotidianas. La aplicación del cuestionario EQ-5D-5L para medición de calidad de vida es una herramienta fácil de aplicar que debería realizarse rutinariamente para planear intervenciones dirigidas a mejorar la atención médica.

\section{Palabras clave}

Pancreatoduodenectomía; calidad de vida; complicaciones; cuestionario; morbilidad.

\section{INTRODUCTION}

Cephalic duodenopancreatectomy (DPC or Whipple procedure) has undergone several technical transformations since it was originally described over one century ago. This procedure us indicated for pancreatic neoplasms, and less often for chronic pancreatitis or cystic lesions. (1) The initial mortality was of around $30 \%$ and there are current reports of up to $4 \%$ in high volume institutions; however, the mortality ranges between 30 and $60 \%$. (2) The most frequent postoperative complications are delayed gastric emptying, pancreatic fistula and surgical wound infection, which reflects in the rate of readmissions, reinterventions and longer hospital stay. These aspects impact the patient's quality of life, which is extremely important but seldom assessed. (3)
Historically, in 1948, the world Health Organization (WHO) defined health as "a state of complete physical, mental and social well-being and not merely the absence of disease or infirmity". (4) Later, this definition was accompanied by the term quality of life, which evolved from a conceptual definition to a series of scales and questionnaires used to measure the overall perception of the individual, in terms of functionality, pain, disability, and mental state. $(5,6)$ Moreover, the ongoing technological evolution and target therapies of cancer patients - including pancreatic cancer - have been able to improve their survival and long term results. However, these pathologies are accompanied by distressing symptoms that negatively affect functionality and quality of life, even long after the initiation of treatment, with an impact not just on the patient, but on the family and the people around them. (7)

Patient reported outcomes (PRO), in terms of medical therapy-associated quality of life, may be considered a compensation measurement between the benefit of surviving, the toxicity of the treatment, and the physical and emotional wellbeing of patients. (8) Currently there are a number of generic, multidimensional instruments and designed for all types of cancer, an even for chronic pathologies.

There are several studies - with controversial reports - in terms of quality of life after DPC due to adenocarcinoma or chronic pancreatitis with discretely lower scores in the quality of life indicators as compared against patients undergoing laparoscopic cholecystectomy. (9) However, another prospective trial in patients with pancreatic resection (68\% due to 
pancreatic adenocarcinoma) showed that the quality of life decreases during the three postoperative weeks, but then return to the preoperative baseline levels and is maintained for up to six months- (10) Moreover, Ruckert et al., in a retrospective trial with 67 patients undergoing DPC due to chronic pancreatitis, quality of life was evaluated using a measurement instrument comparing against healthy volunteers and found that most patients obtained similar results and were able to satisfactorily return to their activities of daily living. (11)

With this background, the purpose of this trial was to compare the groups of patients to whom the same instrument was administered to measure quality of life: one group of patients with DPC and a control group undergoing laparoscopic cholecystectomy in the same hospital. The instrument used was the EQ-5D$5 \mathrm{~L}$ questionnaire (12-14), validated for Colombia and designed by EuroQol Croup. The underlying hypothesis was that patients undergoing DPC could have the same perceptions in terms of quality of life, as those undergoing laparoscopic cholecystectomy.

\section{MATERIALS AND METHODS}

A retrospective cohort trial was conducted, reviewing all patients who underwent DPC by the hepatobiliary surgical team (HPB), between July 2018 and February 2020, and the management of the condition in an institution in Medellín (Colombia). All the procedures analyzed were performed by the same surgical team made up by two surgeons and two anesthesiologists, specialized in HPB. The selection criteria were defined as follows: 1) Inclusion criteria: patients programmed for DPC, regardless of the type of pathology (benign, malignant) and age over 18 years old; and 2) exclusion criteria: carcinomatosis or vascular infiltration that required cancelling the surgery. The quality of life data collection was conducted during April 2020 and a minimum follow-up of 2 months was required. All variables, except exposure to the quality of life questionnaire, were accurately collected from each patient's electronic medical record, and the reviewers never reassessed the diagnoses or any other information already recorded in the medical charts. The groups were defined as patients undergoing DPC and the control group was patients undergoing laparoscopic cholecystectomy secondary to gallbladder lithiasis, matched by gender, age and date of the intervention. Secondary source data were assessed, such as the demographic characteristics, diagnosis, length of hospital stay, and 60-day mortality.

In order to measure the quality of life reports by patients, an authorization was requested from the EuroQol research foundation (EuroQol Office, Marten Meesweg 107, 3068 AV Rotterdam, The Netherlands) in order to administer the EQ5D-5L questionnaire. An approved version of the questionnaire translated into Spanish was approved by expert consultants specialized to produce a language adaptation prepared and approved for Colombia since 2012 (registry number 34496). (13,14)

This health questionnaire was administered over the telephone to all patients by one of the investigators, other than the patient's treating physician, to avoid interviewer bias. The questionnaire is made up of five questions or quantitative dimensions and are related to quality of life, at the time of administering the questionnaire. These dimensions are: 1) Mobility, 2) Personal Care, 3) Activities of Daily Life, 4) Pain/Discomfort and 5) Anxiety/depression. Each dimension includes 5 possible answers and the patient may only select one answer per dimension to describe his/her best health status (for instance, Mobility: 1: I do not have a problem to walk, 2: I have mild problems to walk, 3: I ha e moderate problems to walk, 4: I have severe problems to walk 5: I am unable to walk). The last question is a numeric quantitative scale reflecting the overall health status scored from 0 to 100 , where $o$ represents the worst imaginable health and 100 the best imaginable health; every patient is required to give his/her numeric answer.

For the sake of completeness of this article, the STROBE guide for cohort trials was used. The data collection and analysis were approved by the Ethics Committee of Clínica CES, on March 10, 2020 and in accordance with the legal provisions that govern the scientific, technical and administrative standards for health research, under Resolution 8430 of 1993 , whereby this research project is considered risk-free. The verbal informed consents were obtained over the telephone, prior to administering the quality of life questionnaire.

The analysis took into account the characteristics of the variables and used the SPSS software version 20.0 to process the information. In terms of the quantitative variables, the corresponding central tendency and dispersion measurements were used, in accordance with their distribution, using the KolmogorovSmirnov test, expressed as medians and interquartile range (IQR). With regards to the qualitative variables, the description was made in terms of absolute and relative frequencies; a bivariate exploratory analysis is presented. The quality of life variable was dichotomized due to the patient's failure to select an answer in some of the dimensions evaluated. Hence, the score for the first 44 dimensions of the EQ-5D-5L questionnaire was classified as: 1) I do not have any problems or I have mild problems, and 2) I have moderate, severe, or serious problems, resulting in a dichotomic variable for these dimensions. These variables were analyzed via a comparison of proportions, with the independence Pearson's statistical Chi squared, using the lowest risk variable as a reference value (I do not have any problems or I have mild problems), the raw odds ratios (OR) are calculated with the corresponding $95 \%$ confidence intervals (95\% Cl) using $2 \times 2$ tables. For the better health variable score, the bivariate analysis was conducted using the Mann-Whitney $U$ test. An alpha value of less than 0.05 was considered statistically significant. 


\section{RESULTS}

Sixty-eight patients met the inclusion criteria from July 2018 through February 2020, 6 of which failed to answer the telephone call $y$ 5 passed away. The EQ-5D-5L questionnaire was administered to 57 patients (Figure 1). Of the 5 patients who died, only 1 was classified as death in less than 60 days; the rest were all beyond 60 days.

In the terms of the demographic and clinical characteristics of the 68 patients in the initial cohort, 30 (44.1\%) underwent DPC surgery and 38 (55.8\%), underwent laparoscopic cholecystectomy; they were matched by age gender, and date of the procedure, with a 1:1 an approximate ratio (0.78). $63.2 \%$ of the total cohort of patients were females, with a mean age of 60 years. The most frequent diagnosis in the DPC group was pancreatic cancer (30\%), followed by papillary adenocarcinoma $(26,7$ $\%$ ); while in the cholecystectomy group, the most frequent diagnosis was lithiasis (100 $\%)$. The hospital stay for the DPC group was 7 days (IQR 5-11) and in the cholecystectomy group was 1 day (IQR 0-1). The 60-day mortality was $3.3 \%(n=1)$ for the DPC group, and o for the control group (Table 1).

The PRO evaluation based on the EQ5D-5L questionnaire showed the prevalence

FIGURE 1. Study flowchart.

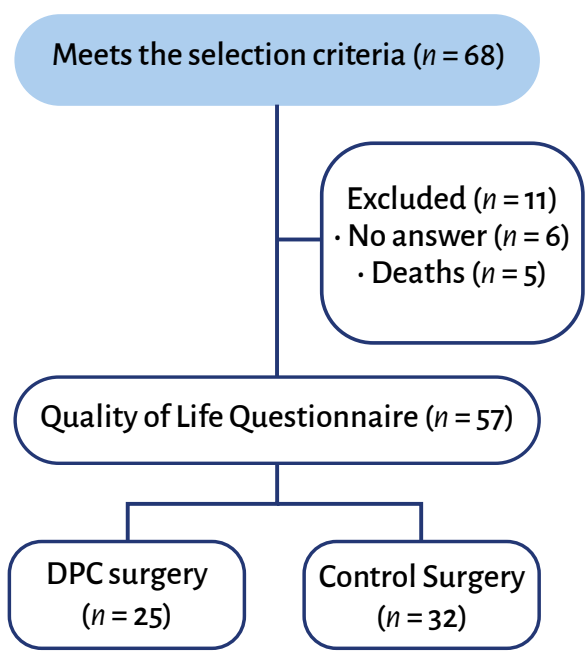

DPC: Cephalic duodenopancreatectomy. SOURCE: Authors. of the first two answer options, which qualitatively are a higherscore (Table 2). The re-categorized questionnaire is presented in a dichotomous fashion based on the patient's answer - in accordance to the description under Materials and Methods as: 1) I do not have any problems or I have mild problems, and 2) I have moderate, severe or serious problems. The results for mobility were OR: $0.41,95 \% \mathrm{Cl}[0,30-0,57]$, $p=0.103$ ) and for personal care, OR: $0.42,95$ $\% \mathrm{Cl}$ [0.32-0.58], $\mathrm{p}=0.254$; most patients in both the DPC and cholecystectomy groups said "I do not have any problems or I have mild problems", and these measurements do not show any significant differences. With regards to measurements about daily life activities, the results were: OR: $0.38,95$
$\% \mathrm{Cl}[0.27-0.54], \mathrm{p}=0.017$; pain/discomfort: OR: 2.33, $95 \% \mathrm{Cl}$ [0.99-5.48], $\mathrm{p}=0.013$; and for anxiety/depression, the OR: 0.39 , $95 \% \mathrm{Cl}$ [0.28-055], $\mathrm{p}=0.019$, evidencing differences between DPC surgery and the control group (Table 3).

The participants expressed that their overall health perception was 80 points for Whipple (IQR 60-90) versus 100 points for the control group (IQR 90-100) $(p=0.003)$; however, both scores are close to the best score (100 points).

\section{DISCUSSION}

There is a limited number of studies on our population assessing the quality of life of patients after DPC, as compared

TABLE 1. Demographic and clinical characteristics $(n=68)$.

\begin{tabular}{|c|c|c|c|c|}
\hline \multirow[b]{2}{*}{ Characteristics } & \multicolumn{2}{|c|}{$\begin{array}{c}\text { DPC } \\
(n=30)\end{array}$} & \multicolumn{2}{|c|}{$\begin{array}{c}\text { Laparoscopic } \\
\text { cholecystectomy }(n=38)\end{array}$} \\
\hline & $n$ & $\%$ & $n$ & $\%$ \\
\hline Female & 15 & 51.7 & 26 & 71.8 \\
\hline Age* & 59 & $50-60$ & 60 & $48-68$ \\
\hline \multicolumn{5}{|l|}{ Diagnosis } \\
\hline Lithiasis & 0 & 0 & 38 & 100 \\
\hline Pancreatic cancer & 9 & 30.0 & 0 & 0 \\
\hline Papillary adenocarcinoma & 8 & 26.7 & 0 & 0 \\
\hline Duodenal tumor & 2 & 6.7 & 0 & 0 \\
\hline Distal cholangiocarcinoma & 2 & 6.7 & 0 & 0 \\
\hline IPMN & 2 & 6.7 & 0 & 0 \\
\hline NET. head of the pancreas & 2 & 6.7 & 0 & 0 \\
\hline Chronic pancreatitis & 1 & 3.3 & 0 & 0 \\
\hline Chronic pancreatitis + IPMN & 1 & 3.3 & 0 & 0 \\
\hline Locally advanced adenocarcinoma & 1 & 3.3 & 0 & 0 \\
\hline Retroperitoneal tumor & 1 & 3.3 & 0 & 0 \\
\hline Solid pancreatic pseudopapillary tumor & 1 & 3.3 & 0 & 0 \\
\hline Length of stay * & 7 & $5-11$ & 1 & $0-1$ \\
\hline 60-day mortality & 1 & 3.3 & 0 & 0 \\
\hline
\end{tabular}

"Median (IQR), DPC: Cephalic duodenopancreatectomy; IPMN: Intraductal papillary mucinous neoplasm; NET: Neuroendocrine tumor. SOURCE: Authors. 
TABLE 2. Quality of Life Questionnaire EQ-5D-5L ( $n=57)$.

\begin{tabular}{|c|c|c|c|c|}
\hline \multirow[t]{2}{*}{ Questionnaire EQ-5D-5L } & \multicolumn{2}{|c|}{$\begin{array}{c}\text { DPC } \\
(n=25)\end{array}$} & \multicolumn{2}{|c|}{$\begin{array}{l}\text { Laparoscopic } \\
\text { Cholecystectomy }(\mathrm{n}=32)\end{array}$} \\
\hline & $n$ & $\%$ & $n$ & $\%$ \\
\hline \multicolumn{5}{|l|}{ Mobility } \\
\hline I have no problems to walk & 19 & 76 & 32 & 100 \\
\hline I have mild problems to walk & 4 & 16 & 0 & 0 \\
\hline I have moderate problems to walk & 1 & 4 & 0 & 0 \\
\hline I have severe problems to walk & 1 & 4 & 0 & 0 \\
\hline I am unable to walk & 0 & 0 & 0 & 0 \\
\hline \multicolumn{5}{|l|}{ Personal care } \\
\hline I have no problem to shower or get dressed & 20 & 80 & 32 & 100 \\
\hline I have mild problems to shower or get dressed & 4 & 16 & 0 & 0 \\
\hline I have moderate problems to shower or get dressed & 1 & 4 & 0 & 0 \\
\hline I have severe problems to shower or get dressed & 0 & 0 & 0 & 0 \\
\hline I am unable to shower or get dressed & 0 & 0 & 0 & 0 \\
\hline \multicolumn{5}{|l|}{ Activities of daily life } \\
\hline I have no problem to conduct my activities of daily life & 17 & 68 & 32 & 100 \\
\hline $\begin{array}{l}\text { I have mild problems to conduct my activities of } \\
\text { daily life }\end{array}$ & 3 & 12 & 0 & 0 \\
\hline $\begin{array}{l}\text { I have moderate problems to conduct my } \\
\text { activities of daily life }\end{array}$ & 1 & 4 & 0 & 0 \\
\hline $\begin{array}{l}\text { I have serious problems to conduct my activities } \\
\text { of daily life }\end{array}$ & 3 & 12 & 0 & O \\
\hline I am unable to conduct my activities of daily life & 1 & 4 & 0 & 0 \\
\hline \multicolumn{5}{|l|}{ Pain/Discomfort } \\
\hline I have no pain or discomfort & 10 & 40 & 25 & 78.1 \\
\hline I have mild pain or discomfort & 4 & 16 & 3 & 9.4 \\
\hline I have moderate pain or discomfort & 6 & 24 & 3 & 9.4 \\
\hline I have strong pain or discomfort & 4 & 16 & 1 & 3.1 \\
\hline I have extreme pain or discomfort & 1 & 4 & 0 & 0 \\
\hline \multicolumn{5}{|l|}{ Anxiety/ Depression } \\
\hline I am not anxious or depressed & 17 & 68 & 31 & 96.9 \\
\hline I am slightly anxious or depressed & 4 & 16 & 1 & 3.1 \\
\hline I am moderately anxious or depressed & 1 & 4 & 0 & 0 \\
\hline I am very anxious or depressed & 3 & 12 & 0 & 0 \\
\hline I am extremely anxious or depressed & 0 & 0 & 0 & 0 \\
\hline Score Best imaginable health* & 80 & $60-90$ & 100 & $90-100$ \\
\hline
\end{tabular}

*Median (IQR), DPC: Cephalic duodenopancreatectomy.

SOURCE: Authors. to a control group, using the EQ-5D-5L questionnaire. In has been found that in general these patients report a slightly lower quality of life than the control group, which emphasizes the need to adopt in our medical practice the use of tools organize and classify this information, with a view to improving healthcare processes and perioperative follow-up. (15)

DPC is a complex and high-risk procedure, indicated for pancreatic adenocarcinoma, ampullary carcinoma, ampullary adenoma, neuroendocrine tumors, cholangiocarcinoma, duodenal neoplasm, pancreatic and/or duodenal trauma, and chronic pancreatitis. (16) High volume centers report a mortality of $4 \%$, and up to $50 \%$ morbidity as a result of pancreatic fistula and/or gastric emptying disorders. Additionally, there are long-term consequences ranging from malnutrition - associated with weight loss and malabsorption - to the need for micronutrient supplementation. The 5 year survival es between 20 and $30 \%$, depending on the tumor localization: $22 \%$ for localized, $9 \%$ for locoregional and $2 \%$ for metastatic disease. (17-19) In contrast, cholecystectomy is a common, intermediate risk surgery, usually laparoscopic, with the advantages of a lower postoperative pain incidence and shorter hospital stay, in addition to faster return to normal activities. (20) This is because the metabolic stress levels (activation of the sympathetic system) are lower the first day after surgery, in contrast to the open technique, where these levels normalize after three days. (21)

With regards to cancer, its therapy involves physical complications, psychological alterations typical of this diagnosis, and toxic effects due to medications affecting functionality and quality of life. Therefore, management should not only focus on the disease, but in the resulting experience and the consequences on the patient and his/her environment. (7) It is important to know the short-term results of the surgical outcome of patients undergoing DPC and validate the impact on quality of life and functionality, that can be measured 
TABLE 3. EQ-5D-5L questionnaire based on patients' answers $(n=57)$.

\begin{tabular}{|c|c|c|c|c|c|c|}
\hline \multirow[t]{2}{*}{ EQ-5D-5L Questionnaire } & \multicolumn{2}{|c|}{$\begin{array}{c}\text { DPC } \\
(n=25)\end{array}$} & \multicolumn{2}{|c|}{$\begin{array}{c}\text { Laparoscopic } \\
\text { Cholecystectomy }(\mathrm{n}=32)\end{array}$} & \multirow[b]{2}{*}{ OR (IC $95 \%)^{1}$} & \multirow[b]{2}{*}{$p$} \\
\hline & $n$ & $\%$ & $n$ & $\%$ & & \\
\hline \multicolumn{5}{|l|}{ Mobility } & $0.41[0.30-0.57]$ & 0.103 \\
\hline None or mild & 23 & 92 & 32 & 100 & & 100 \\
\hline $\begin{array}{c}\text { Moderate. severe } \\
\text { problems or unable }\end{array}$ & 2 & 8 & 0 & 0 & & 0 \\
\hline \multicolumn{5}{|l|}{ Personal care } & $0.42[0.32-0.58]$ & 0.254 \\
\hline None or mild & 24 & 96 & 32 & 100 & & 0 \\
\hline Moderate. severe. or unable & 1 & 4 & 0 & 0 & & 0 \\
\hline \multicolumn{5}{|l|}{ Activities of daily life } & $0.38[0.27-0.54]$ & 0.008 \\
\hline None or mild & 20 & 80 & 32 & 100 & & 100 \\
\hline Moderate. severe. or unable & 4 & 16 & 0 & 0 & & 0 \\
\hline \multicolumn{5}{|l|}{ Pain/discomfort } & $2.50[1.52-5.94]$ & 0.007 \\
\hline None or mild & 14 & 56 & 28 & 87.5 & & 0 \\
\hline Moderate. severe. or unable & 11 & 44 & 4 & 12.5 & & 0 \\
\hline \multicolumn{5}{|l|}{ Anxiety/depression } & $0.39[0.28-0.55]$ & 0.019 \\
\hline None or mild & 21 & 84 & 32 & 100 & & 100 \\
\hline $\begin{array}{c}\text { Moderate. very or extremely } \\
\text { anxious }\end{array}$ & 4 & 16 & o & o & & 0 \\
\hline $\begin{array}{l}\text { Score general health } \\
\text { status }^{2}\end{array}$ & 80 & $\begin{array}{l}60- \\
90\end{array}$ & 100 & $90-100$ & - & 0 \\
\hline
\end{tabular}

1Independence Pearson's statistical Chi squared; ${ }^{2}$ Median (IQR); DPC: Cephalic duodenopancreatectomy. SOURCE: Authors.

in terms of satisfaction with treatment outcomes, disability, mood disorders, and associated pain. (22)

The evaluation of the patient's functional status, the social factors and his/ her expectations should be an integral part of the comprehensive health assessment, since these may affect the postoperative outcomes, as shown by Kim et al., in a literature review that showed that patients who readmitted after seven postoperative days, were mostly associated with social and family factors, while readmission before seven days were associated with loss of independence, and these were linked to increased mortality. (23)

The surgical outcomes or the effects of therapy may be measured through the PRO, though these are not necessarily the questionnaires, the patient should be informed about their objective, since in many cases these questionnaires will be administered periodically. (7)

There are several forms available in the literature to assess the PROs. A measurement instrument EQ-5D (EuroQol until 1996) was developed in 1990 and comprises two parts: a descriptive system EQ-5D and a Visual Analogue Scale (VAS). This is a standardized, self-administered, patient-friendly questionnaire, available in 170 languages. The version EQ-5D-5L was introduced in 2009, which included a 5-dimension assessment (mobility, personal care, activities of daily life, pain/ discomfort, and anxiety/depression), each one of them comprises 5 items to describe the problem (no problem, mild, moderate, severe problems and disability). (24)

The best timing for data collection varies according to the disease and the procedure; questionnaires should be administered individually to each patient, to avoid perception errors. The PROs may be distributed via email, telephone calls, text messaging, videoconferencing, or direct interview, in order to get immediate feedback on the patient's current condition. The information collected may be put to multiple uses, including research, quality improvement of care, cost auditing and evaluation. These data focused on patient experience represent feedback about medical care and help to improve clinical management processes. (25)

There are controversial reports in the literature about quality of life and DPC. In 2000, Huang et al., conducted a trial to assess quality of life of patients after DPC. The sent out a questionnaire with three focus areas: physical, 15 items; psychological, 10 items; social, 5 items to 192 patients, and the resulting scores were 78 $\%, 79 \%$ and $81 \%$, respectively. These scores were similar to the those obtained from laparoscopic cholecystectomy groups and groups of healthy volunteers and showed that patients after DPC could satisfactorily return to their daily activities, with scores that were slightly lower than those of 
other groups assessed. (9) In this trial, the general perception about the health status was lower among DPC patients versus the laparoscopic cholecystectomy patients, mostly because of poorer scores with regards to pain/discomfort and anxiety/ depression.

With regards to the quality of life questionnaires, in 2016 Basch et al, selected 766 patients receiving chemotherapy for solid tumors - breast, genitourinary, gynecological and lung - to be administered a measurement tool (EQ-5D) and report about worsening of symptoms to their doctors before the consult or to continue with the traditional control visits system. The treating physicians received alert messages due to worsening of symptoms, based on the answers to the questionnaire so that they could improve their care.

This study showed that those patients to whom the questionnaire was administered, reported better quality of life ( $34 \%$ vs. $18 \%$; $\mathrm{p}<0.001$ ) as compared to the control group; this was a consequence of the symptoms report via the questionnaire. (26). Heerkens et al., between March 2012 and July 2016, assessed the association between quality of life measured with the EORTC-QLQ-C3O questionnaire (European Organization for Research and Treatment of Cancer Quality of Life Questionnaire-) and the impact of postoperative complications in accordance with the Clavien-Dindo classification in 137 patients undergoing pancreatic cancer surgery. $50 \%$ of the patients presented at least one serious complication over the first 12 months following surgery. However, there were no quality of life-associated differences between the two groups. (27)

A more recent study by Sutton at al., including 35 colon cancer patients undergoing surgery, showed that the PRO metrics using EQ-5D questionnaires, in addition to other psychosocial validation parameters, enabled the identification of patients with unmet needs and postoperative difficulties. This led to the implementation of processes to design additional therapies focused on the medical gaps and ratified PRO as a promising longterm follow-up tool. (28)

When comparing the various instruments to measure PRO, such as EQ5D-5L, EQ-5D-3L and EORTC-QLC-C 30 , using logistic regression models, the result was that the instruments with the lowest underestimation of the results - in terms of quality of life assessment was EQ-5D-5L; consequently, we decided to use this questionnaire for this study. (12) This research project found that the administration of the questionnaire enabled the identification of a slightly lower perception of the overall healthcare status by patients undergoing DPC, in contrast with the laparoscopic cholecystectomy patients. It should be highlighted that 20 $\%$ of the DPC group of patients reported strong and extreme pain, leading to assess the need to refer these patients to chronic pain management services during their follow-up, in order to mitigate this perceptions and lead to the development of new management policies. The literature says that pain relief after pancreatic surgery due to chronic pancreatitis may be variable - between $62 \%$ and $85 \%$-, which leaves behind a number of patients experiencing chronic pain.

Risk factors for persistent pain even after one year of surgery have been identified, specifically in cases of pancreatic inflammation: long time between the onset of symptoms and surgery (over 3 years); use of preoperative opioids, and more than five endoscopic procedures. (29) In a 15-year follow-up trial including 166 patients undergoing DPC due to chronic pancreatitis, the study showed that un to $13 \%$ of the patients continued using opioids chronically and $16 \%$ were unable to satisfactorily return to their regular activities. (30) All of these data point to the need to change the management policies for these patients, and to involve additional services such as long-term pain management clinics.

Moreover, the results of this research project show a significant level of anxiety/ depression in these patients, which is consistent with the literature - between 30 and $50 \%$-, when the cause is related to cancer. (31) These symptoms usually begin before surgery and biological and molecular association have been suggested as the causal agents - overexpression of the indolamine dioxygenase enzyme, disruption in the serotonin synthesis, increased levels of metabolites such as quinolinic acid, but there are no conclusive studies to be able to establish a specific pharmacological therapy. (32) Patients at high risk of depression and/ or anxiety should be promptly identified preoperatively, in order to deliver holistic care - including psychological support throughout their treatment - since such conditions affect not just the quality of life, but long-term survival, cognition and immune system function. (33)

The major limitation is that this is an observational trial with a secondary source that could be biased, since the information was not collected based on the objectives of the trial; likewise, there is information bias, specifically the participants' memory to complete the quality of life questionnaire, in addition to the absence of a serial evaluation which hinders the identification of changes over time, since this is a dynamic measurement. Further studies are required - probably multicenter trials - since this research project was conducted in just one clinical center, with specific characteristics and a multidisciplinary team that could not be available in other places. The decision was made to use the EuroQol Group questionnaire, which is a generalized and multidimensional instrument; however, it is important to validate these results through other instruments designed to measure PRO in patients undergoing DPC.

\section{CONCLUSIONS}

Patients undergoing DPC have an overall health perception slightly lower than patients undergoing laparoscopic cholecystectomy. This difference is mainly 
due to increased pain, anxiety/depression and limitation in their activities of daily life. No differences were identified in terms of mobility and personal care.

The use of the EQ-5D-5L questionnaire for measuring quality of life is easy and should be administered routinely, both among inpatients as well as among outpatients, taking into account that these measurements contribute with valuable information when considering intervention activities in patients, such as liaison with pain clinic and psychological assessment, so that they can be used as a reference for new management protocols focused on quality of life.

\section{ETHICAL RESPONSIBILITIES}

\section{Protection of persons and animals}

The authors claim that no experiments in humans or animals were conducted for this research project.

\section{Confidentiality of the information}

The authors declare that they followed all the protocols applicable in their institution for the publication of patient data.

\section{Right to privacy and informed consent}

The authors declare that no patient date have been published in this article.

\section{ACKNOWLEDGEMENTS}

\section{Contributions}

JPAL: Study concept, design and plan; data collection, analysis and interpretation of the data, drafting of the manuscript, approval of the final manuscript.

CQV: data collection, analysis and interpretation of the information, drafting of the manuscript, approval of the final manuscript.

PSZ: statistical analysis, analysis and interpretation of the results, drafting of the results, drafting of the manuscript, approval of the final manuscript.

\section{Contributions to the study}

None declared.

\section{Financial support and sponsorship}

The author declare they received no funding.

\section{Conflict of interests}

The authors declare not to have any conflict of interest to disclose.

\section{Presentations}

None declared.

\section{Appreciation}

None declared.

\section{REFERENCIAS}

1. Are C, Dhir M, Ravipati L. History of pancreaticoduodenectomy: early misconceptions, initial milestones and the pioneers. HPB. 2011;13(6):377-84. doi: http://doi.org/10.1111/ j.1477-2574.2011.00305.x.

2. Xiong ], Szatmary $P$, Huang $W$, de la Iglesia-García D, Nunes QM, Xia Q, et al. Enhanced recovery after surgery program in patients undergoing pancreaticoduodenectomy: A PRISMA-compliant systematic review and meta-analysis. Medicine. 2016;95(18):e3497. doi: http://doi.org/10.1097/ MD.0000000000003497
3. Kagedan D], Ahmed M, Devitt KS, Wei AC. Enhanced recovery after pancreatic surgery: a systematic review of the evidence. HPB. 2015;17(1):11-6. doi: http://doi.org/10.1111/ hpb.12265

4. WHO. Summary Report on proceedings minutes and final acts of the International Health Conference. Int Heal Conf [internet]. 1946;(2):143. Disponible en: http://apps.who. int/iris/bitstream/10665/85573/1/Official_record2_eng.pdf

5. Nelson EC, Landgraf JM, Hays RD, Wasson JH, Kirk JW. The functional status of patients. How can it be measured in physicians' offices? Med Care. 1990;28(12):1111-26.

6. Cruz Bermúdez HF, Moreno Collazos JE, Angarita Fonseca A. Medición de la calidad de vida por el cuestionario QLQ-C30 en sujetos con diversos tipos de cáncer de la ciudad de Bucaramanga-Colombia. Enfermería Global. 2013;12(30):294-303.

7. Mooney K, Berry DL, Whisenant M, Sjoberg D. Improving cancer care through the patient experience: How to use patient-reported outcomes in clinical practice. American Society of Clinical Oncology Educational Book. 2017;(37):695-704. doi: http://doi.org/10.1200/ EDBK_175418

8. Deshpande P, Sudeepthi BI, Rajan S, Abdul Nazir C. Patient-reported outcomes: A new era in clinical research. Perspectives Clin Res. 2011;2(4):137. doi: http://doi.org/10.4103/22293485.86879

9. Huang J], Yeo C], Sohn TA, Lillemoe KD, Sauter PK, Coleman J, et al. Quality of life and outcomes after pancreaticoduodenectomy. Ann Surg. 2000;231(6):890-8. doi: http://doi. org/10.1097/00000658-200006000-00014

10. Mbah N, Brown RE, St. Hill CR, Bower MR, Ellis SF, Scoggins CR, et al. Impact of post-operative complications on quality of life after pancreatectomy. JOP. 2012;13:387-93. doi: http://doi.org/10.6092/1590-8577/617

11. Rückert F, Distler M, Hoffmann S, Hoffmann D, Pilarsky C, Dobrowolski F, et al. Quality of life in patients after pancreaticoduodenectomy for chronic pancreatitis. ] Gastrointestinal Surg. 2011;15(7):1143-50. doi: http://doi. org/10.1007/s11605-011-1539-1

12. Khan I, Morris S, Pashayan N, Matata B, Bashir Z, Maguirre J. Comparing the map- 
ping between EQ-5D-5L, EQ-5D-3L and the EORTC-QLQ-C3O in non-small cell lung cancer patients. Health Qual Life Outcomes. 2016;14(1):60. doi: http://doi.org/10.1186/ s12955-016-0455-1

13. The EuroQol Group. Certified Translation: EQ-5D5LSpanish for Colombia. Septiembre de 2012.

14. Herdman M, Fox-Rushby ], Rabin R, Badia X, Selai $C$. Producing other language versions of the EQ-5D. En: Brooks R, Rabin R, de Charro F, editors. The measurement and valuation of health status using EQ-5D: A European Perspective. Dordrecht: Springer Netherlands; 2003. p. 183-9. Disponible en: http://link. springer.com/10.1007/978-94-017-0233-1_11. doi: 10.1007/978-94-017-0233-1_11

15. Browne JP, Cano S], Smith S. Using patient-reported outcome measures to improve health care: Time for a new approach. Med Care. 2017;55(10):901-4. doi: http://doi.org/10.1097/ MLR.0000000000000792

16. Osborne NH, Colletti LM. Chapter 15. Pancreaticoduodenectomy. En: Minter RM, Doherty $\mathrm{CM}$, editores. Current Procedures: Surgery [Internet]. New York, NY: The McGraw-Hill Companies; 2010. Disponible en: accesssurgery. $\mathrm{mhmedical}$.com/content. aspx?aid $=65$

17. Kneuertz P], Pitt HA, Bilimoria KY, Smiley JP, Cohen ME, Ko CY, et al. Risk of morbidity and mortality following hepato-pancreato-biliary surgery. J Gastrointestinal Surg. 2012;16(9):172735. doi: http://doi.org/10.1007/511605-012-1938-y

18. Reyna-Sepúlveda F, Muñoz-Maldonado G, Pérez-Rodríguez E, Hernández-Trejo F, Guevara-Charles A, Hernández-Cuedea MA. Prognostic factors for survival and surgical complications in Whipple's pancreatoduodenectomy during a 10-year experience. Cirugía y Cirujanos. 2019;87(2):1233. doi: http://doi. org/10.24875/CIRU.18000526
19. Laitinen I, Sand J, Peromaa P, Nordback I, Laukkarinen J. Quality of life in patients with pancreatic ductal adenocarcinoma undergoing pancreaticoduodenectomy. Pancreatology. 2017;17(3):445-50. doi: http://doi.org/10.1016/j.pan.2017.02.013

20. Joshi MR, Bohara TP, Parajuli A, Rupakheti $S$. Surgeon's physical and mental stress while performing laparoscopic cholecystectomy. ] Kathmandu Med Coll. 2017;4(4):111-7. doi: http://doi.org/10.3126/jkmc.v4i4.18251

21. Luo K. Operative stress response and energy metabolism after laparoscopic cholecystectomy compared to open surgery. World ] Gastroenterol. 2003;9(4):847. doi: http://doi. org/10.3748/wjg.v9.i4.847

22. Calabro KA, Raval MV, Rothstein DH. Importance of patient and family satisfaction in perioperative care. Seminars in Pediatric Surgery. 2018;27(2):114-20. doi: http://doi.org/10.1053/j.sempedsurg.2018.02.009

23. Kim S, Duncan P, Groban L, Segal H, Abbott R. Development and implementation of a tool to assess patient-reported outcome measures (PROM) in preoperative setting. Global ] Perioperative Med. 2017;1(1):017-21. doi: http:// doi.org/10.17352/gjpm.000005

24. Cabasés ]M. El EQ-5D como medida de resultados en salud. Gaceta Sanitaria. 2015;29(6):401-3. doi: 10.1016/j.gaceta.2015.08.007

25. Kingsley C, Patel S. Patient-reported outcome measures and patient-reported experience measures. BJA Education. 2017;17(4):13744. doi: http://doi.org/10.1093/bjaed/mkw060

26. Basch E, Deal AM, Kris MG, Scher HI, Hudis CA, Sabbatini P, et al. Symptom monitoring with patient-reported outcomes during routine cancer treatment: A randomized controIled trial. J Clin Oncol. 2016;34(6):557-65. doi: http://doi.org/10.1200/JCO.2015.63.0830
27. Heerkens H, Van Berkel L, J Tseng D, Monninkhof E, Santvoort H, Hagendoorn $\mathrm{H}$, et al. Long-term health-related quality of life after pancreatic resection for malignancy in patients with and without severe postoperative complications. HPB. 2018;20(2):188-95. doi: http://doi.org/10.1016/j.hpb.2017.09.003

28. Sutton PA, Bourdon-Pierre R, Smith C, Appleton $\mathrm{N}$, Lightfoot T, Gabriel C, et al. Evaluating unmet needs in patients undergoing surgery for colorectal cancer: a patient reported outcome measures study. Colorectal Disease. 2019;21:797-804. doi: http://doi.org/10.1111/codi.14599

29. Sinha A, Patel YA, Cruise $M$, Matsukuma $\mathrm{K}$, Zaheer A, Afghani E, et al. Predictors of post-operative pain relief in patients with chronic pancreatitis undergoing the frey or Whipple procedure. ] Gastrointestinal Surg. 2016;20(4):734-40. doi: http://doi. org/10.1007/s11605-016-3081-7

30. Croome KP, Tee M, Nagorney DM, Truty M], Reid-Lombardo Km, Que FG, et al. Pancreatoduodenectomy for chronic pancreatitis-results of a pain relief and quality of life survey 15 years following operation. ] Gastrointestinal Surg. 2015;19(12):2146-53. doi: http://doi. org/10.1007/s11605-015-2928-7

31. Lounis L, Aurran-Schleinitz T, Turrini O, Delpero J-R, Bréjard V. Psychological outcomes and quality of life in relation to pancreatectomy: A systematic review. Pancreas. 2019;48(4):471-9. doi: http://doi. org/10.1097/MPA.0000000000001279

32. Barnes AF, Yeo TP, Leiby B, Kay A, Winter JM. Pancreatic cancer-associated depression: A case report and review of the literature. Pancreas. 2018;47(9):1065-77. doi: http://doi. org/10.1097/MPA.0000000000001148

33. Marinelli V, Secchettin E, Andrianello S, Moretti C, Donvito S, Marchegiani G, et al. Psychological distress in patients under surveillance for intraductal papillary mucinous neoplasms of the pancreas: The "Sword of Damocles" effect calls for an integrated medical and psychological approach a prospective analysis. Pancreatology. 2020;20(3):505-10. doi: http://doi.org/10.1016/j.pan.2020.01.006 